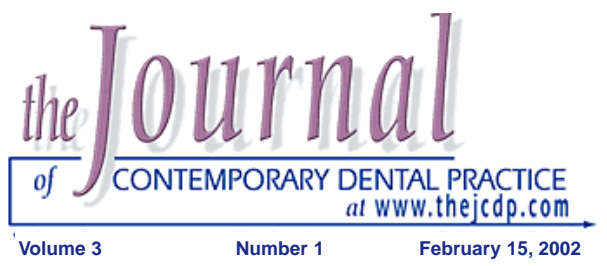

\title{
Managing Practice Statistics for Practice Success
}

\section{Steven Schwartz, DDS}

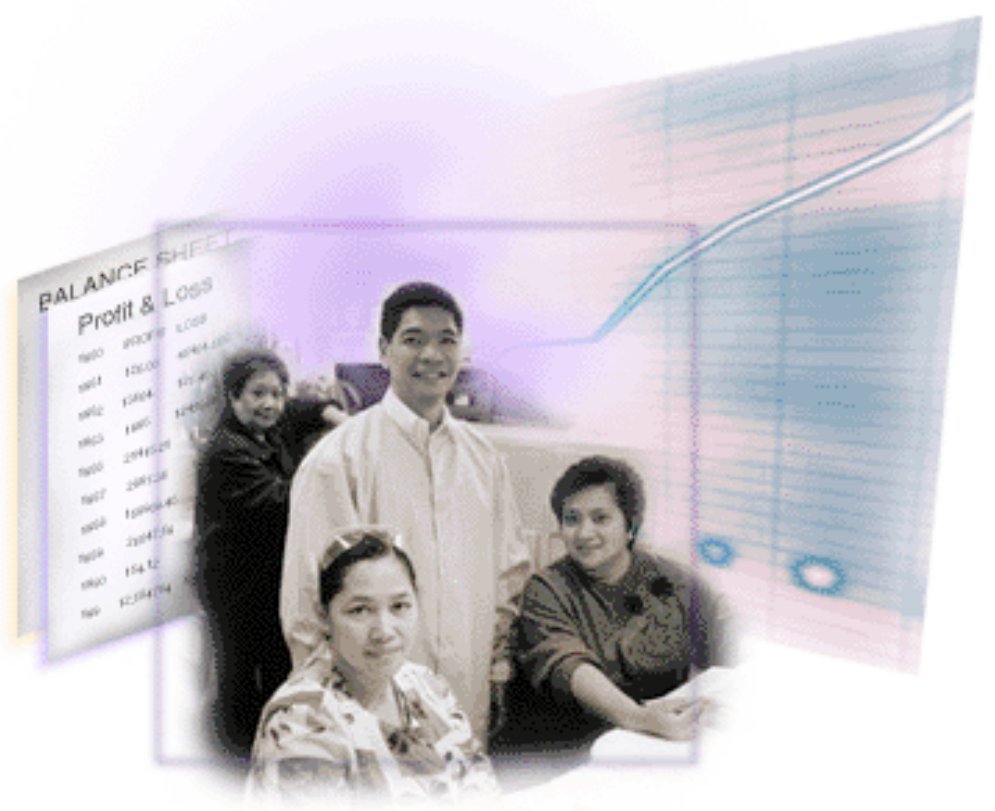

Abstract

The incorporation of computers into the dental practice has enabled the dentist and staff to quickly access information vital to monitoring practice growth and vitality. Despite the fact this information is available at the click of a mouse, the information available to the dentist and staff is often ignored. Even if an effort is made to assess the data, the dental team is clueless on how to use it to control changing economics in the practice. This is accomplished by charting statistical data collected by the dentist and staff. Compilation of this data enables the dentist and staff to recognize trends that will affect the growth and profitability of the practice and develop strategies that reinforce positive trends and reverse negative trends. This paper discusses the value of using data as a tool for practice management.

Keywords: Dental, practice management, statistics, trends

Citation: Schwartz S. Managing Practice Statistics for Practice Success. J Contemp Dent Pract 2002 Feb;(3)1: 055-068.

(C) Seer Publishing 


\section{Introduction}

The incorporation of the use of computers into the dental practice has enabled the dentist and staff to quickly access information vital to monitoring practice growth and vitality. Despite the fact this information is available at the click of a mouse, the information available to the dentist and staff is often ignored. Even if an effort is made to assess the data, some dental teams are clueless on how to use it to control changing economics in the practice.

Just as former mayor of New York City, Ed Koch would greet his constituents by asking them "How am I doing?", in dentistry, the same is accomplished by asking for opinions from patients by using customer satisfaction surveys. However, surveys alone do not provide a true picture of how a practice is doing. They only provide subjective information that is based on personal perspectives of patients. The dentist and staff may be popular with patients, but the health and vitality of the practice is not revealed. Objective information is needed to monitor practice growth.
This is accomplished through the collection and charting of statistical data about the practice. Compilation of these data enables the dentist and staff to recognize trends that will affect growth and profitability. They are also used to develop strategies that reinforce positive trends and reverse negative trends.

While the numbers of statistical areas that can be studied might seem limitless, the evaluation and control of the practice can be accomplished by studying just a few statistics to determine how they relate to each other.

\section{Income Vs Expense Data}

The major indicator of practice health is profit (or loss). 1 The amount of profit a practice exhibits is based on income minus costs (overhead). When income is greater than overhead, there is a profit. Conversely, when income is less than overhead, there is a loss. The amount of income and overhead are determined by a number of factors.

These factors and how they impact on each other are illustrated in Figure 1.

Figure 1. Factors Influence Practice Profit (loss)

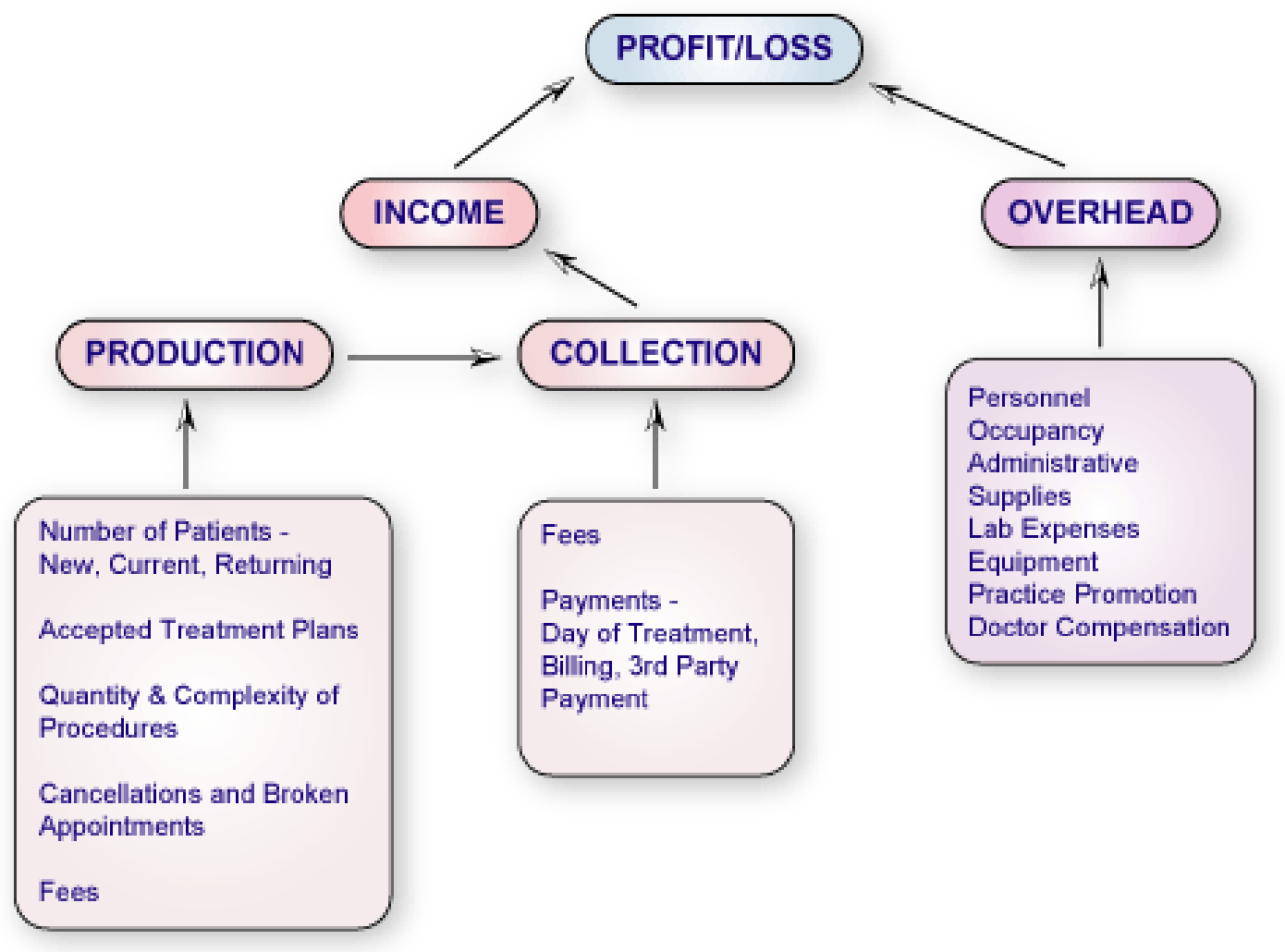


Income is determined by the collection of fees generated through the production of services. In an ideal world the fees collected would be equal to production. While few practices exist in this ideal world, many come close. The amount of production generated is affected by a number of factors. These include:

- The number of patients (new, current, returning)

- The number of accepted treatment plans

- The quantity and complexity of treatment rendered

- Cancellations and broken appointments

- Fees charged

The amount of fees collected is affected by the amount of production and additional factors.

These factors are:

- Fees

- Successful collection of fees generated by production (accounts receivable

- management and insurance claim processing).

Practice overhead consists of expenditures for the following:

- Personnel

- Occupancy (rent, mortgage, utilities, repairs)

- Administrative expenses

- Supplies (clinical and clerical)

- Lab expenses

- Equipment (purchase, lease, maintenance)

- Practice promotion

- Doctor compensation
These factors and sub-factors are divided into two groups: positive statistics and negative statistics. As the numeric value of a positive statistic increases, the health and growth of the practice increases. Conversely, as the numeric value of a negative statistic increases, the health and growth of the practice decreases.

\section{Tracking the Data}

For the practice to benefit from statistical analysis, it is imperative the dentist and the staff are involved in the tracking of the statistics. Weekly and monthly data are collected and recorded by the dentist and staff. The financial administrator is responsible for monthly production and collections. Hygienists track new and recall patients. The scheduling coordinator monitors broken appointments and cancellations. The dentist is responsible for overhead. The information gathered by these individuals is shared with the whole team at monthly meetings.

The statistical data collected is recorded on a graph as shown in Figure ${ }^{2}$. Just as a picture is worth a thousand words, data expressed in a linear graph is easier to visualize and, thus, more comprehensible than looking at a bunch of numbers and enables the team to track trends and make the necessary adjustments. Every statistic that is tracked has its own graph except for collection and overhead, which are recorded on the same graph. The graph produced provides greater visualization of the profit and loss for the practice.

Figure 2. Trends

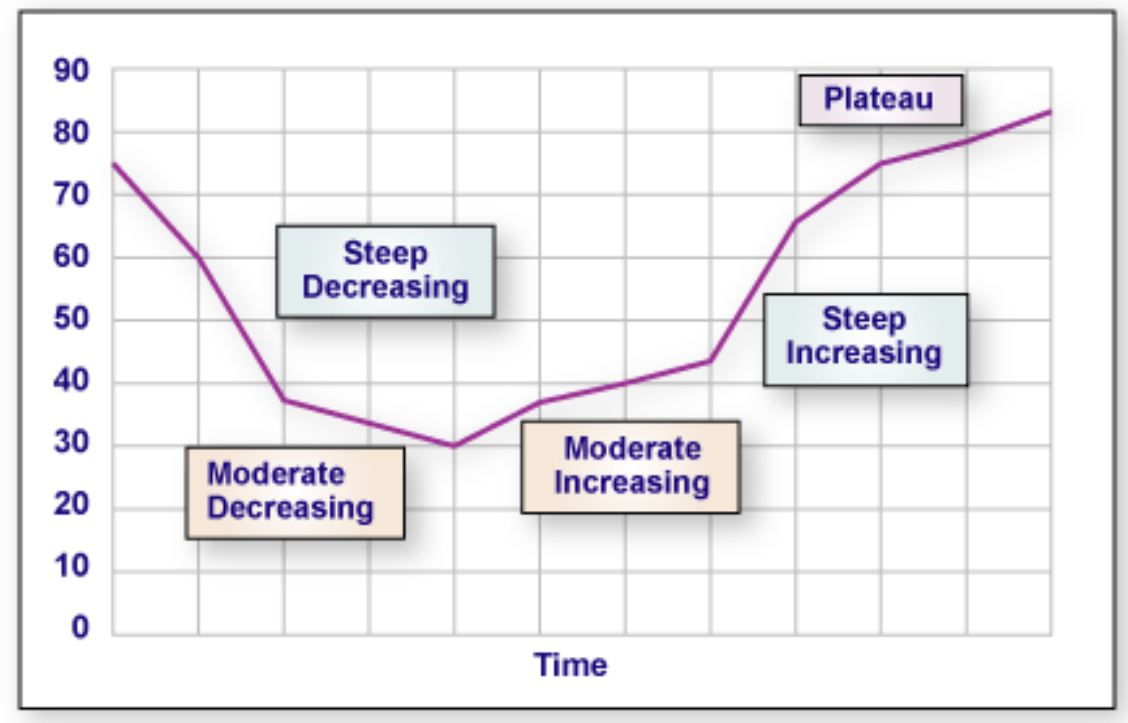


The horizontal axis of the graph represents "time;" each division representing days, weeks, or months. The vertical axis represents the value of the measured statistic; each division representing the measured statistic. The highest and lowest division should be approximately twice the average values of the collected data. For example, when charting monthly production in a practice producing $\$ 50,000$ per month, the divisions on the vertical axis range from zero to one hundred thousand. In a graph measuring the number of new patients per month in a practice with 30 new patients a month, the divisions run from zero to 60 . Over time, as the statistic approaches either end of the scale, the divisions are adjusted.

\section{Data Analysis}

Each month the statistics information are collected, recorded, plotted on the graph, and analyzed by the entire staff. A comparison is made to the previous month's data and the previous year's data. The staff also determines whether a trend is developing. A trend develops when a statistical value increases, decreases, or remains the same over a two-month period. Trends are grouped into five categories:

- Steep decreasing

- Moderate decreasing

- Moderate increasing

- Steep increasing

- Plateau

If a statistic is increasing or decreasing at a rapid rate, it is steep. If it is increasing or decreasing at a slower rate, it is moderate. A plateau trend occurs when a steep trend tapers into a moderate trend. The rate of increase or decrease of a trend is calculated by measuring the angle between lines formed by a trend and the horizontal axis. A steep trend has an angle greater than 45 degrees, and a moderate trend has an angle less than 45 degrees.

\section{Responding to the Data}

Once the trend is categorized, specific steps are taken to control and modify it. ${ }^{2,3}$ The four steps are:

1. Assign Responsibility Depending on the category of the trend, the dentist or a staff member takes overall responsibility for investigating and, if necessary, modifying the trend.
2. Identify the Problem Identify the area causing the problem. The dentist and staff investigate the factors responsible for the trend. Trends and statistics of other areas of the practice are examined and compared. For example, if there is a drop in collection, a corresponding reduction in the number of insurance claims processed may point to the cause of the problem.

3. Take Action

Do whatever action is necessary to correct the problem identified in Step 2. This may include increasing external and internal marketing, increasing the number and type of procedures performed, increased training for the entire team, changing office policy, or insuring that current office policy is observed.

4. Monitor the Situation Depending on the category of the trend, the statistic may be monitored daily, weekly, or monthly. In a steeply decreasing trend, the statistics are monitored daily or weekly. In a moderately decreasing trend, the statistics are monitored weekly. In any category of increasing trends or in a plateau trend, the statistics are monitored monthly.

\section{Steep Decreasing Trends}

For a positive statistic exhibiting a steep decreasing trend, the follow actions are taken:

1. Assign Responsibility. This trend indicates there are major problems

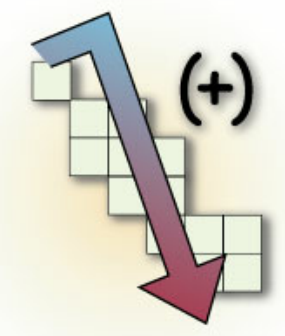
in the practice, and it is imperative that changes be made immediately. The dentist must exhibit strong leadership and control and, for that reason, usurps the authority of other team members in the practice. The dentist undertakes ultimate responsibility for identifying the basis of the trend, changing and instituting practice policies, and monitoring the staff's compliance of instituted procedures and policies.

2. Identify the Problem

The dentist identifies the source of the problem by questioning staff and patients as to their perception of the cause of the 
Table 3. Controlling Trends

\begin{tabular}{|c|c|c|c|c|}
\hline & $\begin{array}{l}\text { STEEP } \\
\text { DECREASIN }\end{array}$ & $\begin{array}{l}\text { MODERATE } \\
\text { DECREASING }\end{array}$ & $\begin{array}{l}\text { MODERATE } \\
\text { INCREASING }\end{array}$ & $\begin{array}{l}\text { STEEP } \\
\text { INCREASING }\end{array}$ \\
\hline Responsibility & Dentist & Staff & Staff & Staff \\
\hline \multirow[t]{2}{*}{ Identify Causes } & $\begin{array}{l}\text { Doctor questions staff to } \\
\text { uncover possible causes. }\end{array}$ & $\begin{array}{l}\text { Staff investigates } \\
\text { possible causes. }\end{array}$ & $\begin{array}{l}\text { Staff identifies areas } \\
\text { doing well and not doing } \\
\text { well }\end{array}$ & $\begin{array}{l}\text { Staff identifies those areas } \\
\text { doing well and not doing } \\
\text { well }\end{array}$ \\
\hline & $\begin{array}{l}\text { Doctor examines stats in } \\
\text { other areas of the practice. }\end{array}$ & $\begin{array}{l}\text { Staff investigates stats } \\
\text { in other areas of the } \\
\text { practice. }\end{array}$ & & $\begin{array}{l}\text { (Most are as will be doing } \\
\text { mell). }\end{array}$ \\
\hline \multirow[t]{4}{*}{ Take Action } & $\begin{array}{l}\text { Promote, produce, } \& \\
\text { reduce overhead. }\end{array}$ & $\begin{array}{l}\text { Do not change office } \\
\text { policies. }\end{array}$ & $\begin{array}{l}\text { Do not make changes in } \\
\text { areas that are doing well. }\end{array}$ & Don't change amything. \\
\hline & Provide training. & $\begin{array}{l}\text { Take corrective } \\
\text { measures to insure } \\
\text { existing policies } \\
\text { are appropriate }\end{array}$ & $\begin{array}{l}\text { Reward staff responsible } \\
\text { for improvement }\end{array}$ & $\begin{array}{l}\text { Pay bilk with high interest } \\
\text { rates }\end{array}$ \\
\hline & Change office policies. & & $\begin{array}{l}\text { Follow steps for } \\
\text { decreasing trends in } \\
\text { areas not doing well }\end{array}$ & $\begin{array}{l}\text { Invest in improving senvice } \\
\text { facilities. }\end{array}$ \\
\hline & & & & $\begin{array}{l}\text { Doctor and staff receive } \\
\text { bonuses and raises }\end{array}$ \\
\hline \multirow[t]{3}{*}{ Monitor the Situation } & $\begin{array}{l}\text { Doctor monitors the } \\
\text { situation and team closeby }\end{array}$ & $\begin{array}{l}\text { Team monitors the } \\
\text { situation }\end{array}$ & $\begin{array}{l}\text { Team monitors the } \\
\text { situation }\end{array}$ & $\begin{array}{l}\text { Team monitors the } \\
\text { situation }\end{array}$ \\
\hline & $\begin{array}{l}\text { Stats monitored daihy and } \\
\text { weekly }\end{array}$ & Stats monitored weekly & Stats monitored monthly & Stats monitored monthly \\
\hline & & $\begin{array}{l}\text { Close monitoring } \\
\text { of the staff is } \\
\text { unnecessany. }\end{array}$ & & $\begin{array}{l}\text { Be prepared to correct a } \\
\text { falling trend }\end{array}$ \\
\hline \multicolumn{5}{|c|}{ PLATEAU } \\
\hline
\end{tabular}

decreasing statistic. The dentist examines statistical trends in all areas of the practice and compares them with each other to isolate problems. For example, if there is a decrease in production, a corresponding decrease in the number of patients returning for their recall exams may suggest a cause for the problem.

3. Take Action

Do whatever is necessary to correct the problem. In the above example the staff surveys patients to see why they are not returning. Are they being contacted by the office to return for recall visits? If not, is it because of a staff problem or procedural problem. If the problem is the result of a team member's failure in following office procedure, the team member is re-educated in office policy or relieved of the responsibility. If office policy is being followed, re-evaluation of the efficacy of the policy may be necessary. In this example, the practice may switch from mailing reminder postcards to patients to pre-appointing patients for their next recall appointment.

4. Monitor the Situation

The dentist undertakes full responsibility for monitoring the trend. Statistics are recorded and examined on a daily or weekly basis.

The staff may still be responsible for gathering the statistics, but the dentist carefully reviews and analyzes the information.

\section{Moderate Decreasing Trends} For a positive statistic exhibiting a moderate decreasing trend, the following actions are taken:

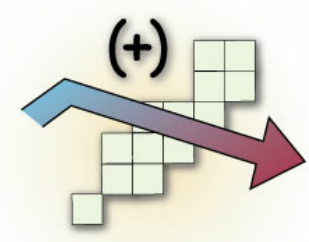

1. Assign Responsibility

As this trend is less critical than the steep decreasing trend, staff members join the dentist in investigating the declining trend. 
2. Identify the Problem

As in the steep decreaing trend, the cause of the problem is identified. In this trend the staff assumes more responsibility. As before, the staff compares the practice trends to isolate problems.

3. Take Action

In a moderately decreasing trend, office policies do not have to be changed just followed. Staff members should be monitored to see if they are following proper procedure. If they are not, they are shown how their actions affect office income and are corrected.

Efforts are made to economize, and supply purchasing is controlled. Purchase just what is needed. The office does not make any major purchases or take on additional debt. Minor adjustments may be needed in opertional procedures and staff responsibilities, but major changes are not needed.

4. Monitor the Situation

Statistics are monitored weekly until the trend becomes positive. The staff is responsible for monitoring the statistics and keeping other staff members apprised of the findings.

\section{Moderate Increasing Trends}

For positive statistics exhibiting a moderate increasing trend, the following steps are taken.

1. Assign Responsibility Both dentist and staff have the responsibility of investigating the moderately increasing trend.

2. Identify

Areas that are doing well and areas that are not doing well are identified and analyzed. Statistics and trends in other areas are compared to each other.

\section{Action}

In areas that are doing well, do not make major changes. Compliment and reward staff members who are responsible for improving a trend. If a statistic is not improving or worsens, find out why and return to the steps outlined in the previous sections.
4. Monitor

The dentist and staff monitor the statisic monthly.

\section{Steep Increasing Trends}

For a positive statistic exhibiting a steep increasing trend, the following actions are taken:

1. Determine Responsibility All staff members are involved with monitoring the steep increasing trend.

2. Identify Identify those areas that are doing well and those that are not, although in this trend most areas often do well.

3. Actions

As in the moderate increasing trend, do not change anything. The dentist and staff should continue doing whatever they have been doing to improve the statistics. For example, if a policy of contacting patients after undergoing difficult treatment was instituted and it resolved a decreasing trend then the policy should continue. Succes should not make the dentist indifferent or careless.

Short-term, high interest debts (credit card, unpaid bills) undertaken in a poor cash flow period are paid first. Investments to improve service facilities that will increase the efficiency and production of the practice are made.

It is not until the previous steps are undertaken do the dentist and staff reward themselves with raises and bonuses.

4. Monitor

Statistics are monitored monthly. The dentist and staff should be prepared to take steps to correct a falling trend.

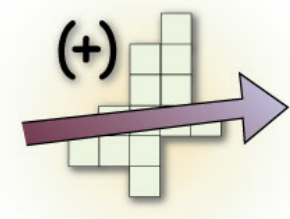

\section{Plateau Trends}

For a positive trend exhibiting a plateau, the following steps are taken:

1. Assign Responsibility All staff members are responsible for investigating the trend. 
2. Identify

A plateau occurs after a steep increasing trend reverts into a moderately increasing trend. The staff must determine if the leveling is due to negative statistics showing increasing influence or is it due to physical or external limitations. For example, a practice that has experienced a steep increase in the number of new patients will eventually be unable to accommodate requests for appointments because of lack of chair time. Increasing the amount of time a patient has to wait for an appointment does not increase production with the accompanying increase in revenues. All it does is put additional stress on the staff responsible for scheduling. The dentist can consider a variety of solutions for accommodating the increased demand for appointments. The dentist can:

- Increase the number of chairs by expanding office space.

- Increase the number of hours devoted to patient care by increasing the dentist's workweek or incorporating an associate dentist or auxiliary staff into the practice.

- Reduce the number of patients by increasing fees.
The first two solutions will eliminate the problem of accommodating patients but may not provide additional profit to the practice because of increased costs for construction, equipment, and personnel. They may also result in increased stress for the dentist and existing staff. The solution of increased fees won't accommodate new patients but will reduce the demand for appointments. The increased fees will result in additional income to the practice with the accompaniment of increased overhead. The ultimate solution rests with the dentist and staff.

When monitoring a negative statistic (overhead, cancellations), the steps are opposite those of a positive statistic.
Negative Statistic
Positive Statistic
If the trend is: steep increasing moderate increasing moderate decreasing steep decreasing
Follow the steps for: steep decreasing moderate decreasing moderate increasing steep increasing

\section{Conclusion}

Just as a person cannot follow a map unless the current location is known, a practice cannot take steps to increase profitability unless it monitors its current position. Monitoring practice growth by statistical data allows the dentist and staff to position the practice for financial success.

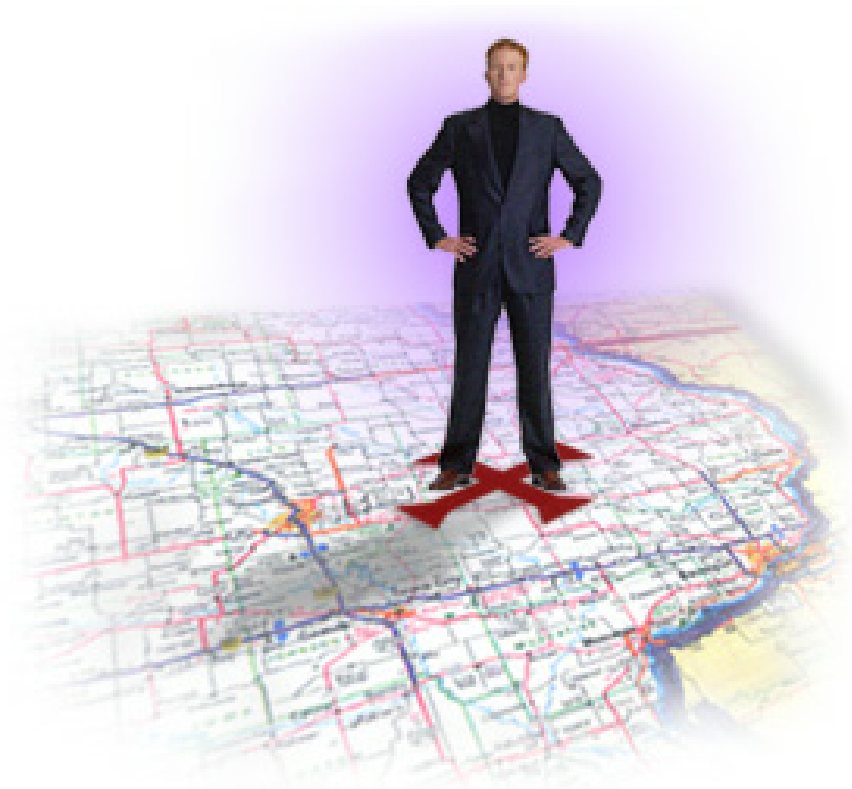

7

The Journal of Contemporary Dental Practice, Volume 3, No. 1, February 15, 2002 


\section{References}

1. The Healthy Company; Robert H. Rosen, St. Martin Press, 1991.

2. Developing Management Skills; David A. Whetten and Kim S. Cameron, Addsion-Wesely Educational Publishers, Inc., 1998.

3. Strategic Planning for the Small Business; Craig S. White, Bob Adams, Inc., 1990.

\section{About the Author}

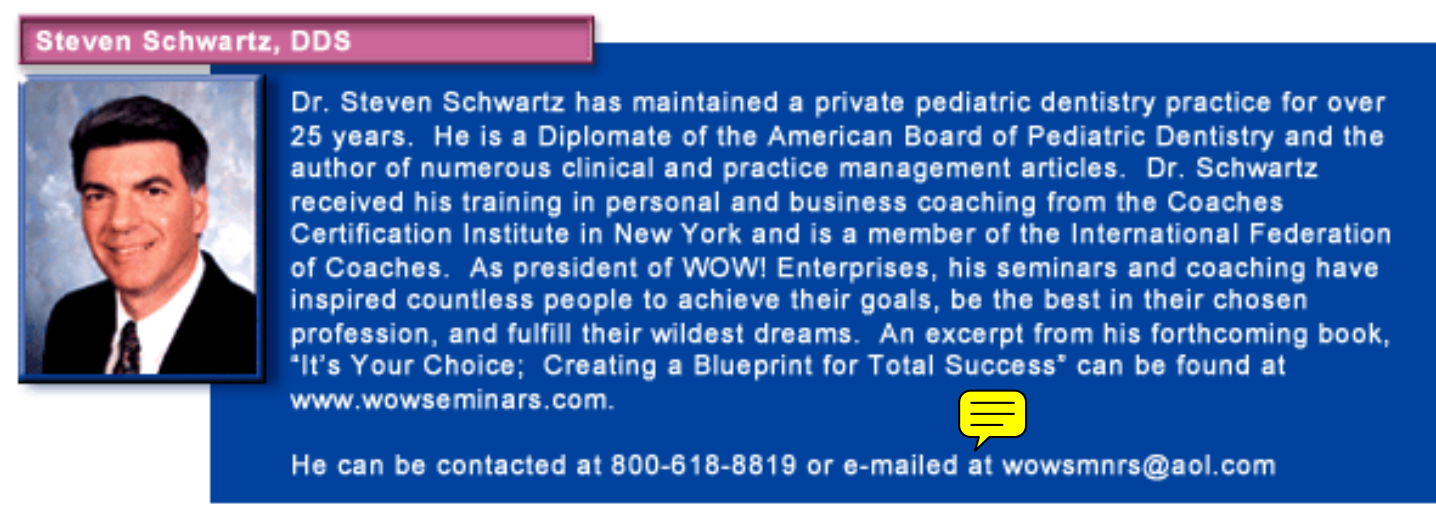

